\title{
Coal Deformation, Metamorphism and Tectonic Environment in Xinhua, Hunan
}

\author{
Huantong Li' ${ }^{1}$, Xiaoyan Zou ${ }^{2}$, Jiafeng $\mathrm{Mo}^{3}$, Yifan Wang1, Fei Chen ${ }^{1}$ \\ ${ }^{1}$ School of Geology and Environment, Xi'an University of Science and Technology, Xi'an, China \\ ${ }^{2}$ College of Geosciences and Surveying Engineering, China University of Mining and Technology, Beijing, China \\ ${ }^{3}$ Academy of Coal Geological Survey of Hunan Province, Changsha, China \\ Email: htlcumt@126.com
}

How to cite this paper: Li, H.T., Zou, X.Y., Mo, J.F., Wang, Y.F. and Chen, F. (2018) Coal Deformation, Metamorphism and Tectonic Environment in Xinhua, Hunan. Journal of Geoscience and Environment Protection, 6, 170-182.

https://doi.org/10.4236/gep.2018.69013

Received: August 17, 2018

Accepted: September 22, 2018

Published: September 25, 2018

Copyright (C) 2018 by authors and Scientific Research Publishing Inc. This work is licensed under the Creative Commons Attribution International License (CC BY 4.0).

http://creativecommons.org/licenses/by/4.0/

\begin{abstract}
This article discusses in detail chemical composition, molecular structure, microstructure phenomena, estimate of the palaeo-stress, paleo-temperature and the strain rate to deepen the knowledge for the correlation of coal deformation and metamorphism with structural environment in Xinhua Hunan by coal quality analysis, XRD and SEM methods, which provide dependable theoretical foundation for coal resource exploitation and utilization. The results show that 1) d002 value of six coal samples is from 3.36 to $3.39 \mathrm{~nm}$, coal resolved itself into aphanitic graphite with the increase of coal rank during coalification, which is characterized by graphite flakes, and the crystallite size is from $50 \mathrm{~nm}$ to $250 \mathrm{~nm}$; A certain degree of $3 \mathrm{R}$-structure content is increases and the crystallite size is extend with the coalification process, but $\mathrm{RH}$-structure content is decreased; 2) the tectonic environment of research area belongs to the ductile-brittle deformation, which was characterized by low temperature, low stress, high strain rate; 3) Tianlongshan magmatic intrusion provided heat source, its side-extrusion made the molecules structure of coal ordering, distance between layers decreased, finally it caused the formation of aphanitic graphite.
\end{abstract}

\section{Keywords}

Coal Deformation and Metamorphism, Tectonic Environment, Aphanitic Graphite, Structural Properties, Xinhua Hunan

\section{Introduction}

Coal is a kind of special rock that is sensitive to temperature and pressure, which will inevitably leave various stress marks in the long geological history. The geo- 
logical environment factors in the kinetics of coal are caused by the changes in the composition and structure of coal, which makes the total entropy of the system negative, and to develop in a more orderly direction (recarburization and graphitization). In recent years, coalification research achievements in foreland basin and thrust nappe tectonic belt of tectonic activity area, reveals the structure-hot events of coal deformation and metamorphism, process control, significantly in coal composition, texture and structure elements of change and migration and accumulation and dispersion [1] [2] [3] [4] [5]. Cao daiyong et al. [6] raised the two basic methods of structural stress affect coal-stress degradation and stress condensation, which was deepen the understanding of the essence of coal-chemical action. At the same time, the microstructure is widely used in the estimation of stress and strain, the inference of deformation environment, deformation process and deformation history. This article uses the coal quality analysis and the experimental test methods such as XRD, SEM, by micro structure analysis, the stress value calculation and research of temperature and strain rate, to reveal the coal deformation metamorphic characteristics relation with tectonic environment, provide the basis for development and utilization of coal resources.

\section{Geological Background and Sample Collection}

\subsection{Geological Background}

Coal samples were collected from the Xinhua mining area. The coal strata measured in this study area are, from bottom to top, the Lower Carboniferous Ceshui Formation and Upper Permian Longtan Formation. Ceshui Formation was the main coal-bearing strata; the main mineable coal seams are 3\#, 5\# coal seams.

In the Xinhua mining area, there are abundant NE- and NNE-trending faults (Figure 1). These NE/NNE-trending faults consist of the Baixi, Dongfu, Banshan, Jijiaoyan, Maoping, Jiyun faults, which are usually overlooked in many literatures, and show a curved band slightly outward to the north west, the main structure is the folding of the imbricated thrust faults and the closed linear folds, and the early folds are severely damaged [7] [8]. In general, the thrust fault is characterized by the spacing distribution of dense bands, each of which is composed of a number of trunk faults and several discontinuous secondary faults.

The tianlongshan rock body is located in the west of the Hanpo'ao syncline, and is cut into a lenticular block by the NE-NNE rending Jiyun fault belt, the age of the zircon $\mathrm{U}-\mathrm{Pb}$ is $196-210 \mathrm{Ma}$ [9], which is indicated that there are strong tectonic activity in Yanshan period and beyond. Due to the thermal metamorphism of magmatic rocks and tectonic extrusion, the deformation metamorphism and metamorphism of the 5\# coal seam in Ceshui Formation of the adjacent rock mass in the cambium are metamorphic and metamorphosed into cryptocrystalline graphite. 


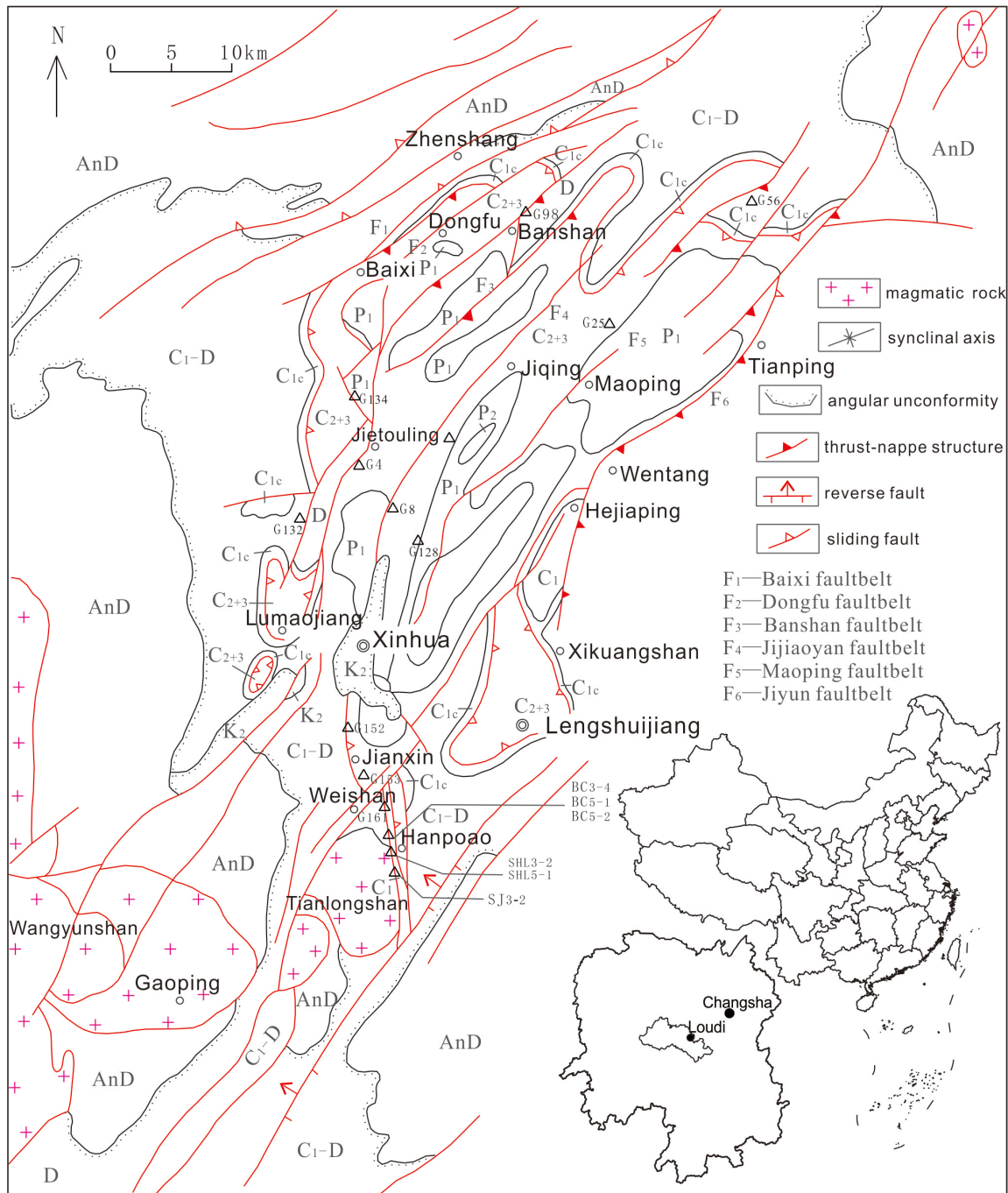

Figure 1. Map of geological structure of Xinhua mining area [7].

\subsection{Sample Collection}

The test samples included coal samples and rock samples examined in this study to give further details of the reasons for coal deformation and metamorphism. Coal samples were collected from Choumu coalmine $+202 \mathrm{~m}$ level, Shengli coalmine $+150 \mathrm{~m}$ level, Bichong coalmine $+170 \mathrm{~m}$ level, Shihangli coalmine $+163 \mathrm{~m}$ level and Shichuan coalmine $+160 \mathrm{~m}$ level with channel sampling method (Sampling size $5 \mathrm{~cm} \times 3 \mathrm{~cm}$ ), all of which are in the Xinhua mining area. Rock samples were collected from neighborhood of faults above-mentioned. Sample locations are show in Figure 1.

\subsection{Coal Deformation Types}

Coal mechanical strength is low, the original structure and chemical composition of coal is changed significantly by multi-stage tectonic stress, the various components of coal petrography are suffer breakage and corrugation under microscope and change to deformed coal. The sheen of coal can be from the bright 
to the dim, and usually the strong structural change will dim the coal's luster; the composition of coal petrography is often cut or broken by fractures, and it is even formed in powder form when it is strongly deformed into fine granules or scales. Ruffled strong coal seam, various components mix together, the structure is more complex, common fragmentation, broken spots, crushed grain, crushed powder, scales; the small deformation is stratified, with irregular mass or powdery structure. The exogenous fissures develop, forming various fractures and forming a fissure network, common irregular sliding mirrors, sometimes visible scratches (Figure 2).

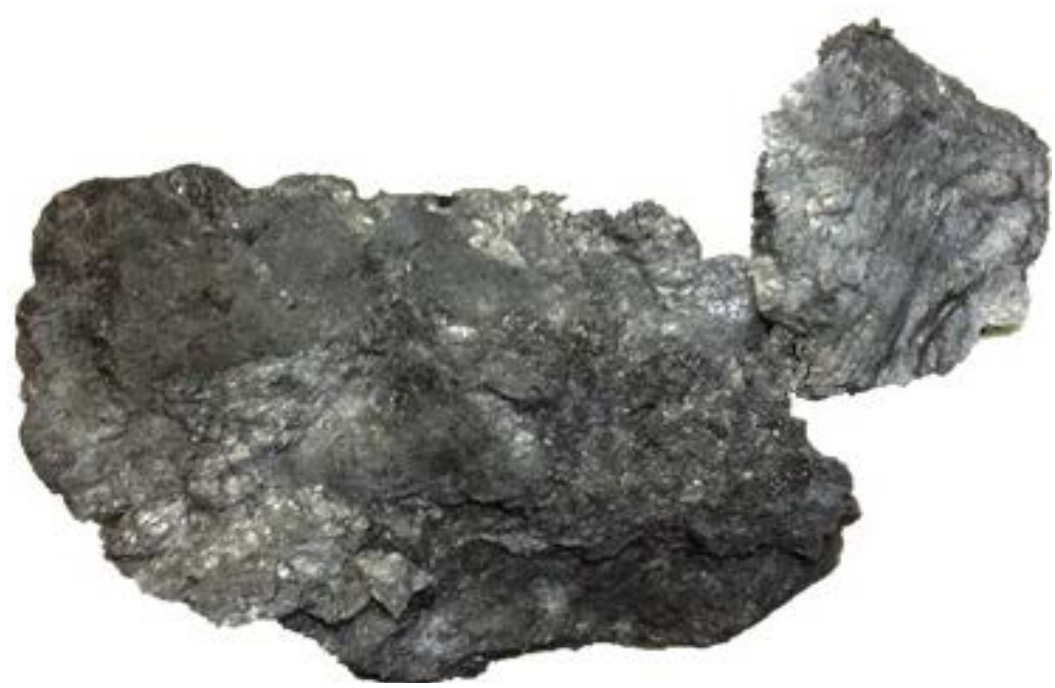

(a)

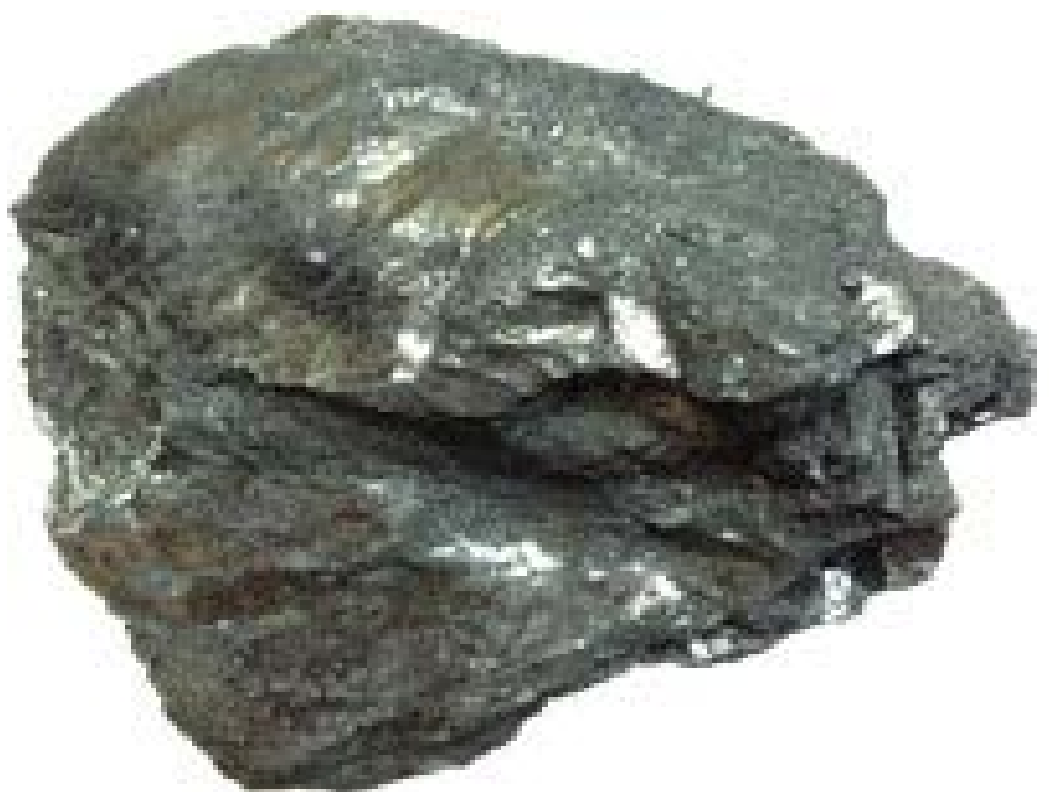

(b)

Figure 2. Macroscopic deformation types of coal samples in Hanpo'ao syncline. (a) Schistose and flaky texture coal in Shengli coalmine; (b) Granulated texture coal in Shichuan coalmine. 


\section{Research of the Coal and Rock Samples Characteristics}

\subsection{Composition Characteristics}

The volatile values of anthracitic coal are less than $10 \%$ and the fixed carbon values are larger than $80 \%$ generally. The volatile values series of coal samples of Hanpo'ao sycline display a decreasing order (i.e., SJ, 3.54\% < SHL, 3.42\% $4.53 \%<\mathrm{BC}, 5.15 \%-5.42 \%$ ) (Figure 1, Table 1), which reflects the gradual increment distance of magmatic rock and metamorphic degree of organic matter. Ceshui Formation is characterized by utral-low and low ash coal, and medium ash coal takes up a small part, only individual coal sample is high ash coal. Ash content of No. 3 coal is relative high and low ash of No. 5 coal. The coal samples in this paper are low sulphur coal, but Tianlongshan coal samples are medium sulphur coal. The correlation of total sulfur and ash content is low; the cause of low sulphur coal may be related to lagoon sea water desalination of marine regression during Ceshui Stage.

\subsection{Structural Characteristics}

\subsubsection{Method}

This experiment was performed using the China University of Mining and Technology (Beijing) State Key Laboratory of Coal Resources and safe Mining's XRD Rigaku D/max-2500 PC, CuK $\alpha$ target, pipe press $36 \mathrm{KV}$, pipe flow $30 \mathrm{~mA}$, launch slit $0.16 \mathrm{~mm}$, step scan, step width $0.04^{\circ}$, scanning speed $2^{\circ} / \mathrm{min}$, low angle diffraction, $2 \theta$ (diffraction angle) is $2^{\circ}-70^{\circ}$, based on the X-ray diffraction spectrum, according to the relevant formula, the basic structure unit parameters of coal samples were calculated and the evolution characteristics of different metamorphic metamorphic coal were analyzed.

Table 1. Chemical composition analysis data of coal samples from different coalmine.

\begin{tabular}{|c|c|c|c|c|c|c|c|c|c|}
\hline \multirow{2}{*}{$\begin{array}{l}\text { Sample } \\
\text { location }\end{array}$} & \multirow{2}{*}{$\begin{array}{l}\text { production } \\
\text { seams }\end{array}$} & \multicolumn{5}{|c|}{ proximate analysis of coal, $\%$} & \multirow{2}{*}{$\begin{array}{c}\text { graphitization } \\
\text { degree }\end{array}$} & \multicolumn{2}{|c|}{ PXRD } \\
\hline & & moisture & $\begin{array}{c}\text { ash } \\
\text { content }\end{array}$ & volatile & $\begin{array}{c}\text { fixed } \\
\text { carbon }\end{array}$ & $\begin{array}{l}\text { total } \\
\text { sulfur }\end{array}$ & & $\mathrm{d}_{002} / \mathrm{nm}$ & $2 \theta$ \\
\hline \multirow{7}{*}{$\begin{array}{c}\text { Hanpo'ao } \\
\text { Sycline } \\
\text { in Xinhua } \\
\text { Hunan }\end{array}$} & SJ3 & 15.63 & 32.79 & 3.54 & 63.67 & 0.57 & 87.7 & 3.3646 & 26.47 \\
\hline & BC5-1 & 1.29 & 11.09 & 5.41 & 83.5 & 0.41 & 61.4 & 3.3873 & 26.29 \\
\hline & BC5-2 & 1.41 & 9.94 & 5.42 & 84.64 & 0.49 & 58.5 & 3.3897 & 26.27 \\
\hline & BC3-4 & 1.81 & 21.79 & 5.15 & 73.06 & 0.80 & 58.6 & 3.3896 & 26.27 \\
\hline & SHL3-2 & 0.80 & 12.85 & 3.42 & 83.73 & 0.42 & 64.4 & 3.3846 & 26.31 \\
\hline & SHL5-1 & 0.33 & 2.71 & 4.53 & 92.76 & 0.20 & 64.4 & 3.3846 & 26.31 \\
\hline & average & 3.55 & 15.20 & 4.58 & 80.23 & 0.48 & 65.83 & 3.3834 & 26.32 \\
\hline
\end{tabular}

Annotation: the coal samples above are tested in National Quality Supervision and Inspection Center of Graphite Products (GB/T3521-2008, YS/T733-2010); graphitization degree $=\left(3.44-\mathrm{d}_{002}\right) /(3.44-3.354)$. 


\subsubsection{Analysis of Experimental Results}

In the process of coalification, as the coal metamorphism increases, the volatilization of coal decreases, the carbon content increases, and the non-anthracite stage contains only the condensed aromatic thick circular structure unit (BSU), the branched chain and various functional groups of the hydrocarbon are gradually decreasing. The carbon network spacing (d002) evolution is very regular-as the coal rank increased, the d002 gradually decreased and eventually became graphite.

According to the results of Han Dexin (1996)'s research on vitrain XRD [10], high-rank coals vitrinite reflectance ( $\mathrm{Ro}, \max$ ) is $>2 \%$, and its d002 value is stable, concentrated in the $3.4-3.6 \mathrm{~nm}$, some scholars also have similar research results [11] [12] [13] [14].

The d002 value of the coal samples in this paper is $3.36-3.39 \mathrm{~nm}$ (Table 1), presents the law of $\mathrm{SJ}<\mathrm{SHL}<\mathrm{BC}$, this trend is due to the local stress field of the structural extrusion of tianlongshan, tectonic compression and superimposed magma tectono-heat, which increased coal aromatic nucleus, layer spacing decreases, and provided evidence for tectonic stress affect the coalification.

From chemical composition (Table 1) and XRD pattern (Figure 3) concluded that the main composition of aphanitic graphite quality is carbon, fixed carbon content was $63.67 \%-63.67 \%$, followed by a small amount of $\mathrm{Fe}_{2} \mathrm{O}_{3}, \mathrm{Al}_{2} \mathrm{O}_{3}, \mathrm{SiO}_{2}$

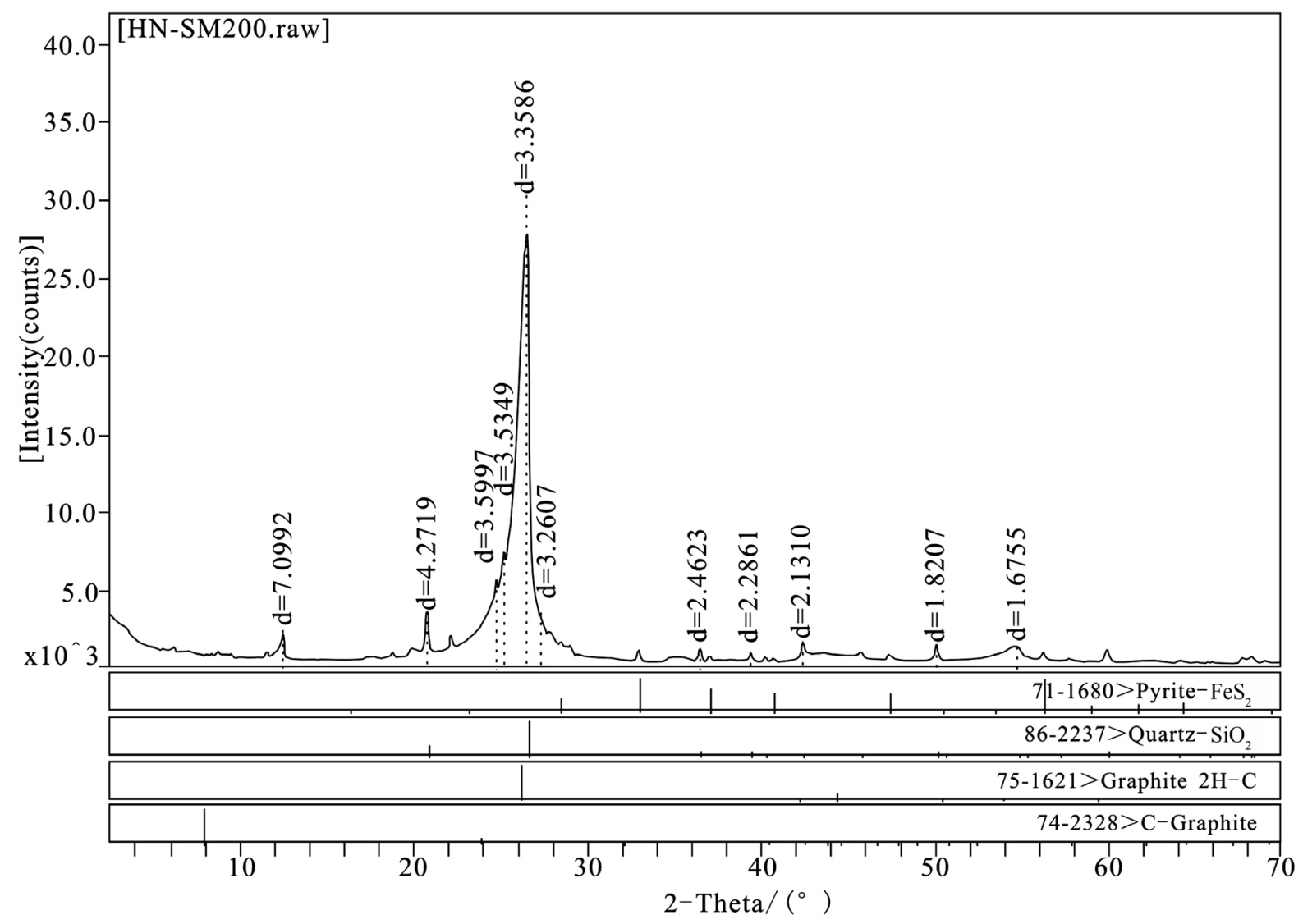

Figure 3. XRD spectra for typical aphanitic graphite in Shengli coalmine, Hanpo'ao syncline. 
etc. inorganic elements, may be associated with the impurities such as quartz and pyrite minerals; In addition, the graphite structure also introduces impurity elements such as S, Al, Si and O.

Graphite type $3 \mathrm{R}(\mathrm{RH})$ variations belong to the metastable phase, when the temperature $\left(\mathrm{T}>2000^{\circ} \mathrm{C}\right)$ disappears, the polymorphism variation in natural graphite structure can't separate separate, its content with increasing degree of coalification (metamorphic grade), graphite crystal quantity increased, the number of $\mathrm{RH}$ phase decreases (Table 2); In this paper, the number of $\mathrm{RH}$ phases in the sample is SJ $<$ TLS $<$ SHL $<$ BC, which reflects the decrease of coal seam degree of coal seam in the water test group to the periphery of the magma intrusion.

\subsection{Morphological Characteristics}

\subsubsection{Method}

The morphological characteristics of coal were found to be related to the deformation and metamorphism mechanism of the coal body structure. Examinations of the morphological characteristics of deformed coal may lay a foundation for the development of control measures. Speciation analysis of deformed coal was performed at the China University of Mining and Technology (Beijing) (Oxford) IE 250 S-3400 SEM.

\subsubsection{Analysis of Experimental Results}

Under the scanning electron microscope of different multiples, crystal pattern shows granulation of aphanitic graphite, the particle is a collection of small scales, partical size is $50-250 \mathrm{~nm}$, mainly includes amorphous forms petaloid ambulacra, lamination, hexagonal schistose (Figure 4).

\subsection{Structural Environment Characteristics}

The formation of deformed microstructures is accomplished by adjusting the internal structure of the rock due to stress under certain conditions [15], the

Table 2. Graphitization degree and content of 3R graphite of the coal samples.

\begin{tabular}{ccccccc}
\hline coal sample location & $\begin{array}{c}\text { sample } \\
\text { numbers }\end{array}$ & $\mathrm{d}_{002} / \mathrm{nm}$ & $\begin{array}{c}\text { graphitization } \\
\text { degree }\end{array}$ & $\mathrm{Rh}(1) / \%$ & $\mathrm{Rh}(2) / \%$ & $\mathrm{Rh} / \%$ \\
\hline & $\mathrm{SJ} 3$ & 3.3646 & 0.877 & 10.297 & 19.494 & 14.895 \\
& $\mathrm{BC} 5-1$ & 3.3873 & 0.614 & 20.497 & 35.029 & 27.763 \\
$\begin{array}{c}\text { Hanpo'ao syncline, } \\
\text { Xinhua, Hunan }\end{array}$ & $\mathrm{BC5}-2$ & 3.3897 & 0.585 & 21.622 & 36.671 & 29.146 \\
& BC3-4 & 3.3896 & 0.586 & 21.583 & 36.602 & 29.093 \\
& SHL3-2 & 3.3846 & 0.644 & 19.334 & 33.181 & 26.257 \\
Tianlongshan, hunan & TLS & 3.372 & 0.5719 & 22.13 & 24.56 & 23.34 \\
$\begin{array}{c}\text { Nanshu, } \\
\text { Shandong }\end{array}$ & SY117-9 & 3.358 & 0.8549 & 11.15 & 14.98 & 13.07 \\
& NSG & 3.366 & 0.6708 & 18.29 & 20.45 & 19.37 \\
\hline
\end{tabular}




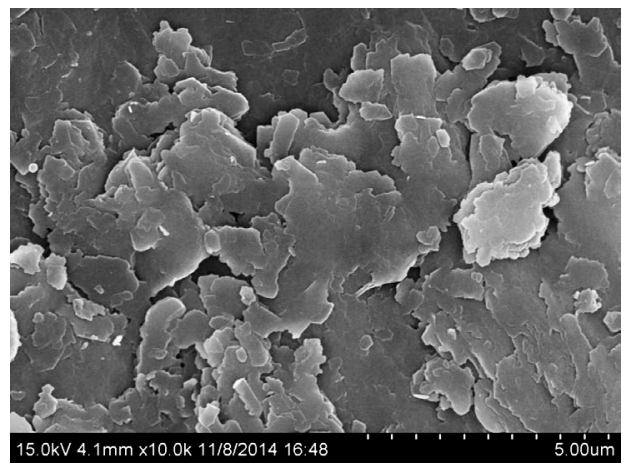

(a)

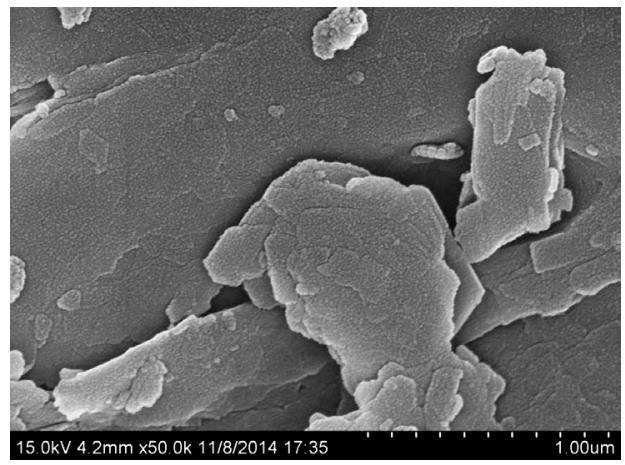

(b)

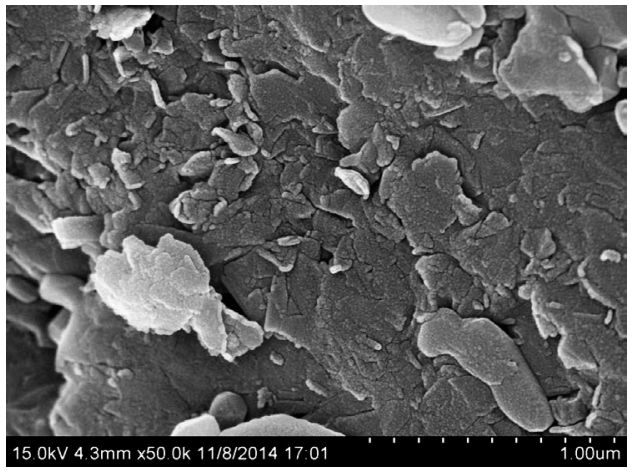

(c)

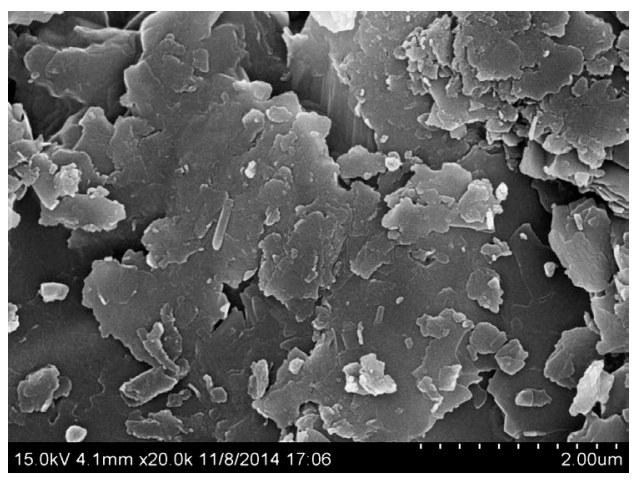

(d)

Figure 4. SEM images for typical coal samples in different coalmines in Hanpo'ao syncline. (a) Shengli coalmine; (b) Choumu coalmine; (c) Shichuan coalmine; (d) Hongshan coalmine. 
deformation mechanisms that have been identified in rocks and other crystalline substance are mainly ruptured, microfracture, dislocations creep (includes dislocation slip and climb), diffusion material migration, particle boundary slip and so on. In rock and other crystalline material at present, the main deformation mechanism has been identified are broken and micro fracture, dislocation creep (including the dislocation sliding and dislocation climb to move), diffusion material migration and grain boundary sliding, etc. The microstructures of the study area are dominated by the two processes (microscopic rupture, crystalline plastic deformation in the extinction, deformation pattern, mechanical twin crystal), they are the result of brittle-ductile transition. Davis and Rernolds discussed the changes in temperature and differential stress conditions of different deformation mechanisms [16], they believed that microfracture and fragmentation and dissolution of creep were mainly manifested in the shallow crust with low temperature and differential stress are relatively high, while the dislocation creep and solid-state diffusion material migration are more in the higher temperature of the deep crust.

\subsubsection{Method}

This experiment was performed using Orthoplan polarizing microscope to quantitatively analyze the rock samples. All rock specimens of collection were horizontal directional cutting. Basic production process: the specimen is fixed with a fine sand pile, the specimen was fixed with fine sand, return to its wild form with a compass, and its horizontal line was marked around the specimen, cut along the horizontal line to get horizontal slices. The microscopic structure of the rock specimen was observed and photographed in the microscope room.

This experiment was performed using Orthoplan polarizing microscope to quantitatively analyze the rock samples.

\subsubsection{Microscopic Structure Analysis}

In the main fault fracture zone, tectonic rocks such as fault breccia, tectonic lens, fractured rock and granulite are developed. Under the polarizing microscope, the phenomenon of common microscopic fracture in tectonite (Figure 5, G56-2, G134), Microscopic fracture appear in the accelerating creep stage due to the adjustment of microscopic deformation mechanism can't keep up with the macroscopic strain velocity discontinuity surface caused by deformation [17], and the study area of quartz development of more wave extinction, deformation patterns, shear cracks and so on (Figure 5, G161, G134, G56-2). It is reflected that the tectonic deformation environment in the study area is generally low temperature and low confining pressure.

\subsubsection{Paleostress Value Estimation}

This paper discussed the brittle tectonic domain dynamics by analysis estimate paleostress value on the basis of twinning of calcite grains percent. The twinning of calcite is common microstructure appearance in shallow structural deformation limestone with the characteristics of low initial temperature $\left(20^{\circ} \mathrm{C}\right)$, small 


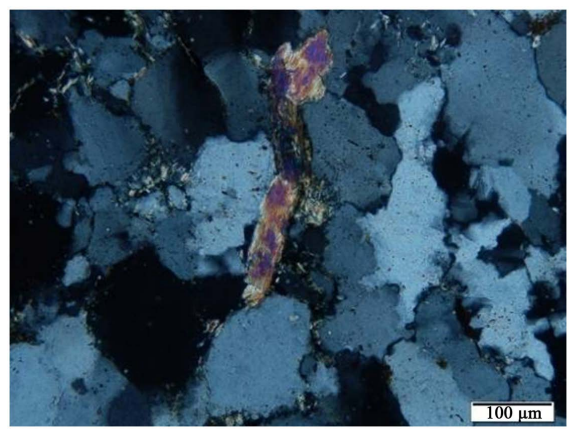

(a)

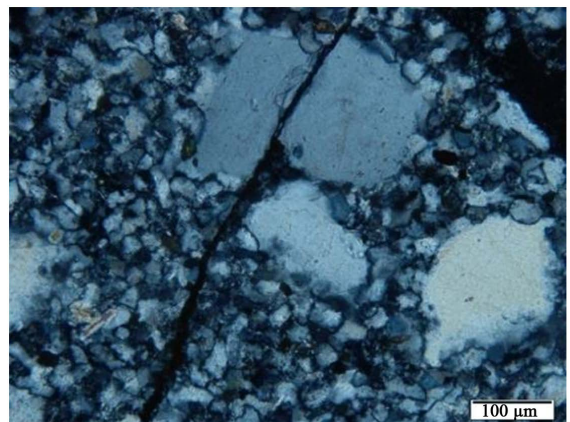

(b)

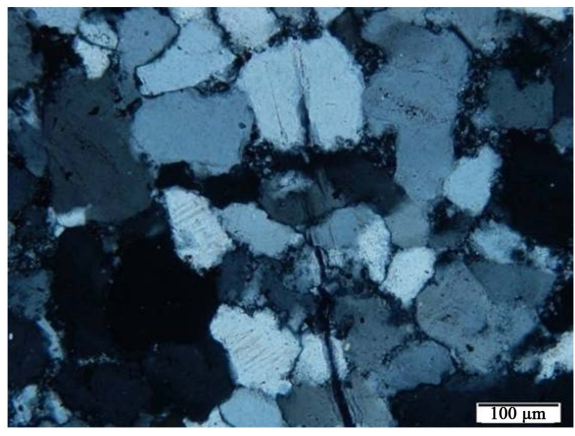

(c)

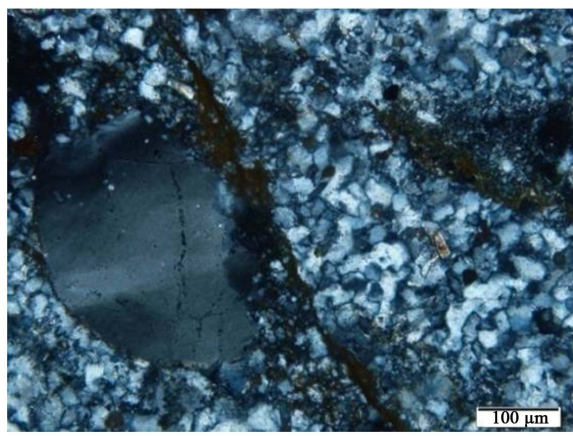

(d)

Figure 5. Microscope deformation in rock samples of Xinhua, central Hunan. (a) G161 plastic deformation-mica kink; Sandstone, Westside of Hanpo'ao syncline; crossed polars; (b) G56-2 boudinage structure of quartz phenocryst sandstone, north of Maoping fault; crossed polars; (c) G134 plastic deformation-quartz intracell deformation lamella; sandstone, south of Banshan fault; crossed polars; (d) G56-2 optical extinction of quartz; sandstone, north of Maoping fault; crossed polars. 
critical shear stress value (10 MPa). Twinning of calcite glide along intracell glide plane under stress action, which must conquer the frictional drag, therefore, degree of twinning development is connected with tectonic stress value $\left(\Delta \sigma=\sigma_{1}\right.$ $\left.\sigma_{3}\right)$.

Xinhua mining area belongs to central Hunan interior deformation zone, the calculating values of stress value focus on 30 - $80 \mathrm{MPa}$ (Table 3), which shows medium-strength strain, extruding strength rises high gradually from east to west. Coalification becomes complication by the interactions with dynamic metamorphism, regional metamorphism and thermal contact metamorphism.

Table 3. Paleo-stress value calculation result by calcite bicrystals percentage.

\begin{tabular}{cccccccccc}
\hline \multirow{2}{*}{$\begin{array}{c}\text { sample } \\
\text { number }\end{array}$} & tectonic location & \multicolumn{2}{c}{$\begin{array}{c}\text { ratio of } \\
\text { bicrystalline } \\
\text { particles }\end{array}$} & \multicolumn{2}{c}{ S1 value } & & \multicolumn{2}{c}{$\Delta \sigma / \mathrm{Mpa}$} \\
\cline { 3 - 8 } & & first & second & first & second & first & second mean \\
group & group & group & group & group & group & value \\
\hline G132 & Baixi Faults & 66 & 25 & 0.19 & 0.12 & 53 & 83 & 68 \\
G17-1 & middle of Jijiaoyan faults & 66 & 15 & 0.19 & 0.17 & 53 & 58 & 55.5 \\
G8-1 & south of Jijiaoyan faults & 50 & 20 & 0.29 & 0.14 & 34 & 71 & 52.5 \\
G128 & south of Jijiaoyan faults & 54 & 16 & 0.26 & 0.16 & 38 & 63 & 50.5 \\
G25-1 & middle of Maoping faults & 52 & 19 & 0.28 & 0.15 & 36 & 67 & 51.5 \\
\hline
\end{tabular}

\section{Conclusions}

1) d002 value of six coal samples is from 3.36 to $3.39 \mathrm{~nm}$ by coal quality analysis, XRD and SEM methods, coal resolved itself into aphanitic graphite with the increase of coal rank during coalification, which is characterized by graphite flakes, and the crystallite size is from $50 \mathrm{~nm}$ to $250 \mathrm{~nm}$, mainly includes amorphous forms petaloid ambulacra, lamination, hexagonal schistose; A certain degree of $3 \mathrm{R}$-structure content is increases and the crystallite size is extend with the coalification process, but $\mathrm{RH}$-structure content is decreased.

2) The tectonic environment of research area belongs to the ductile-brittle deformation, which was characterized by low temperature, low stress, high strain rate; Quartz c-axis fabrics reveals that quartz activity crystal slip system is underside, which is representative of low temperature and high strain rate.

3) Tianlongshan magmatic intrusion provided heat source, its side-extrusion made the molecules structure of coal ordering, distance between layers decreased, finally it caused the formation of aphanitic graphite.

\section{Acknowledgements}

The authors are grateful to the personnel of Academy of Coal Geological Survey of Hunan province, who supplied a great deal of useful information and support during sample collection. This study was financially supported by the NSFC Project (National Science Fundamental of China) No. 41502160. 


\section{Conflicts of Interest}

The authors declare no conflicts of interest regarding the publication of this paper.

\section{References}

[1] Qu, Z.H. (2010) Study of Tectonized Coal Texture and Its Controlling Mechanism upon Gas Properties. China University of Mining and Technology, Xuzhou.

[2] Feng, Y.W., Qu, H.J., Yang, C.Y., et al. (2015) Distribution on Characteristics and Metallogenic Regularity of Graphite Deposits in Qinling Orogen, China. Acta Geologica Sinica, 89, 1244-1263. https://doi.org/10.1111/1755-6724.12526

[3] Li, X., Zeng, F.-G., Wang, W., et al. (2015) FTIR Characterization of Structural Evolution in Low-Middle Rank Coals. Journal of China Coal Society, 40, 2900-2908.

[4] Zhang, X.B., Wang, W., Zhang, Y.G., et al. (2016) Oriented Growth Mechanism of Tectonic Coal Microcrystal. Journal of China Coal Society, 41, 712-718.

[5] Liu, S.Q., Sang, S.X., Wang, G., et al. (2017) FIB-SEM and X-Ray CT Characterization of Interconnected Pores in High-Rank Coal Formed from Regional Metamorphism. Journal of Petroleum Science and Engineering, 148, 21-31. https://doi.org/10.1016/j.petrol.2016.10.006

[6] Cao, D.Y., Zhang, H., Dong, Y.J., et al. (2017) Research Status and Key Orientation of Coal-Based Graphite Mineral Geology. Earth Science Frontiers, 24, 317-327.

[7] Li, H.T., Wang, L.J., Wu, Y.L., et al. (2017) Characteristics and Mechanism of Coal-Controlled Fold-Fault Structure of Lianyuan Depression in Central Hunan Province. Coal Science and Technology, 45, 110-116.

[8] Li, H.T., Cao, D.Y., Wang, L.J., et al. (2013) Characteristics and Evolution of Coal-Controlled Structures on the East Slope of the Xuefengshan Domain in Central Hunan Province. Geotectonica et Metallogenia, 37, 611-621.

[9] Chu, Y., Faure, M., Lin, W. and Wang, Q.C. (2012) Early Mesozoic Tectonics of the South China Block: Insights from the Xuefengshan Intracontinental Orogen. Journal of Asian Earth Sciences, 61, 199-220.

[10] Han, D.X. (1996) Coal petrology of China. China University of Mining and Technology Press, Xuzhou.

[11] Xian, H.Y., Peng, T.J. and Sun, H.J. (2014) Structural Properties Change Comparison between Amorphous and Crystalline Flake Graphite in the Oxidation Process. Non-Metallic Mines, 37, 18-21.

[12] Xian, H.Y., Peng, T.J., Sun, H.J., et al. (2015) Mineralogical Characteristics of Some Typical Graphite Samples in China. Acta Mineralogica Sinica, 35, 395-405.

[13] Xie, Y.Z. and Yan, Y.J. (1989) Study of Tianlongshan Aphanitic Graphite Chemical Composition Analysis and Structural Properties. Carbon, No. 4, 13-17.

[14] Zhou, X.L., He, Y.L. and Liu, H.S. (2017) Geological Characteristics of Coal and Graphite in Hanpoao Mining Area in Northern Section of Lianshao Coalfield of Hunan Province. Coal Geology \& Exploration, 45, 9-13.

[15] Cao, D.Y. and Wang, C.H. (1990) Microstructures and Tectonic Environment of South Henan Fault Zone. Journal of China University of Mining and Technology, 19, 16-23.

[16] Davis, G.H. and Rernolds, S.J. (1996) Structural Geology of Rocks and Regions. 2nd Edition, John Wiley Sons, New York. 
[17] Xu, Z.Q., Wang, Q., Liang, F.H., et al. (2009) Electron Backscatter Diffraction (EBSD) Technique and Its Application to Study of Continental Dynamics. Acta Petrologica Sinica, 25, 1721-1736. 